\title{
Hazardous Characteristics and Safety Management of Toxic Substances
}

\author{
An Zhengyang \\ Trainming dept \\ Kunming Fire Service Training School \\ Kunming, China \\ anzhengyang2005@sina.com
}

\author{
Wang Yuanyuan \\ Training dept \\ Kunming Fire Service Training School \\ Kunming, China \\ 1009541492@qq.com
}

\begin{abstract}
Toxic substances have hazardous characteristics of being flammable in contact with water, oxidative, flammable and explosive. Harm to human and other lives may result from the absence of safety management. After the main hazardous characteristics analysis of toxic substance, safety management was proposed correspondingly.
\end{abstract}

Keywords- Toxic substances; hazardous characteristics; safety management; flammable; explosive

\section{INTRODUCTION}

Toxic substance is referred to the substance which can lead to death, serious injury and health damage of human after being devoured, inhaled and skin-contacted. It includes any solid or liquid satisfying one of the following conditions.

(1) Acute oral toxicity: LD50 $\leq 300 \mathrm{mg} / \mathrm{kg}$;

(2) Acute skin contact toxicity: LD50 $\leq 1000 \mathrm{mg} / \mathrm{kg}$;

(3) Acute inhalation of dust and smoke toxicity : $\mathrm{LC} 50 \leq 4 \mathrm{mg} / \mathrm{L}$;

(4) Acute inhalation of steam toxicity

LC $50 \leq 5000 \mathrm{ml} / \mathrm{m} 3$ under conditions of temperature

$20 \mathrm{oC}$ and concentration of statured steam under standard atmosphere pressure is equal to or above 1/5LC50。

Acute oral toxicity median lethal dose LD50 is referred to the oral amount of a toxic agent (as a poison, virus, or radiation) that is sufficient to kill 50 percent of a population of male or female white mice usually within 14 $\mathrm{d}$. The experimental results are expressed with $\mathrm{mg} / \mathrm{kg}$ body weight. Acute toxicity of skin contact median lethal dose LD50 is referred to the amount of a toxic agent that is sufficient to kill 50 percent of a population of tested animals within $14 \mathrm{~d}$ after continuous contact with naked skin of white mice. The experimental results are expressed with $\mathrm{mg} / \mathrm{kg}$ body weight. Acute inhalation of dust and smoke toxicity LC50 and acute inhalation of steam toxicity LC50 are referred to the concentration of a toxic steam, dust and smoke that is sufficient to kill 50 percent of a population of male or female white mice usually within 14 $\mathrm{d}$ after continuous inhalation of $1 \mathrm{~h}$. The experimental results of dust and smoke are expressed with $\mathrm{mg} / \mathrm{L}$, while that of steam is expressed with $\mathrm{ml} / \mathrm{m} 3[1][2]$.

\section{THE MAIN HAZARDOUS CHARACTERISTICS OF} TOXIC SUBSTANCE

\section{A. Toxicity}

\section{1) Route of intoxication.}

The main hazardous characteristic of toxic substance is its toxicity, which presents as the damage to human and animals though routes of respiratory tract, digestive tract and skin[3].

2) Intoxication of respiratory tract.

Among toxic substances, the vapor of volatile liquid and the dust of solid are most easily into the human body through the respiratory organs. Especially in the process of fire rescue and evacuation of toxic substances, it is very easy to cause respiratory poisoning for firemen for their longer time contacting with toxic substances and a large amount of breathing. Substances, such as hydrocyanic acid, methyl bromide, aniline and arsenic trioxide, can enter into the lungs through the human respiratory tract and be absorbed by the alveolar surface, causing poisoning with the blood circulation. In addition, organs of nose, larynx and trachea mucosa of respiratory tract also have considerable absorption capacity, which is easy to cause poisoning for absorption. Since respiratory poisoning is fast and serious, firemen fighting fire of toxic substance should wear necessary protective equipment, so as not to cause poisoning[4].

3) Intoxication of digestive tract.

Digestive tract poisoning is referred to the poisoning caused by the toxic substances in the the digestive organs of human body. Because the liver has detoxification function of some toxic substances, so the digestive tract poisoning is more slowly than that of respiratory tract. Some toxic substances such as arsenic and its compounds, are insoluble or very low soluble in water. But with the help of gastric juice, they will change into soluble substances which can be absorbed by the body and cause human poisoning[5].

4) Intoxication of skin.

For some toxic substances that can dissolve in water or fat, it is easy to invade the skin and cause poisoning after contact with the skin. Such as aromatic derivatives, nitrobenzene, aniline and benzidine, pesticide of organic phosphorus, mercury and other toxic substances, can invade the human body through the break of the skin, and spread rapidly with the blood circulation. In particular, cyanide poisoning can lead to death in a very rapid way. Moreover, chloroacetophenone and other toxic substances have a great deal of harm to the mucous membranes of the human body, for example cornea[6] .

5) Influencing factors of toxicity.

The toxicity of toxic substance is determined by various factors. After comparative analysis, those influencing factors are summarized as follows[7].

6) Chemical composition and structure. 
It is the basic influencing factor for the toxicity of the toxic substance, which includes aspects as follows.

(1) Saturation level of organic chemicals. For example, the toxicity of acetylene is larger than that of ethylene, while that of ethylene is larger than that of ethane.

(2) Carbon number of hydrocarbon. For example, the toxicity of demeton methyl is less than that demeton ethyl by $50 \%$.

(3) Number of nitro group for nitro compounds. The toxicity increases with the number of nitro group. If there are halogen atoms in the molecular of nitro compounds, the toxicity increases with the number of halogen atoms.

(4) Position of nitro group on the benzene ring. As shown in Table I, due to the different positions of the same nitro group on benzene ring, the toxicity of compounds are different to several times[8].

TABLEI THE EFFECT OF SUBSTANCE STRUCTURE ON THE TOXICITY

\begin{tabular}{|c|c|c|}
\hline Compounds & Structure & $\begin{array}{c}\mathrm{LD}_{50} \\
(\mathrm{mg} / \mathrm{kg})\end{array}$ \\
\hline Parathion & & 18 \\
\hline $\begin{array}{l}o \text {-Nitro- } \\
\text { parathion }\end{array}$ & $\mathrm{H}_{2}-\mathrm{Q}_{\mathrm{H}}^{\mathrm{S}}$ & 50 \\
\hline $\begin{array}{l}m \text {-Nitro- } \\
\text { parathion }\end{array}$ & $\mathrm{S}$ & $100-150$ \\
\hline
\end{tabular}

\section{7) Solubility.}

The greater water solubility the toxic substance has, the easier intoxication happens. Since human body contains large amount of water, it is easy for freely soluble toxic substance to be absorbed by human body. Moreover, except for the water in the blood, gastric juice, lymph and cell sap, human body contains acids and fats, and some toxic substances have greater solubility in them than in water, which can cause intoxication more easily.

8) Volatility.

The greater the volatility of toxic substance is, the greater the toxicity. The reason for this is that the toxic steam resulted from the evaporation of toxic substance is easy to be absorbed by human body through respiratory organ and cause respiratory intoxication. For example, mercury and methyl bromide are strong volatile. The greater concentration of the steam in air is, the easier intoxication happens. Furthermore, the longer residence time is, the easier intoxication happens and the more serious intoxication is[9].

\section{9) Particle size.}

The more fine particles of solid toxic substances, the more likely to cause poisoning. Since fine powder can penetrate packaging easily and be diffused through air flow, especially when the packaging is broken. Moreover, fine particles of toxic substance are easy to be absorbed by human. For example, intoxication cannot happen because

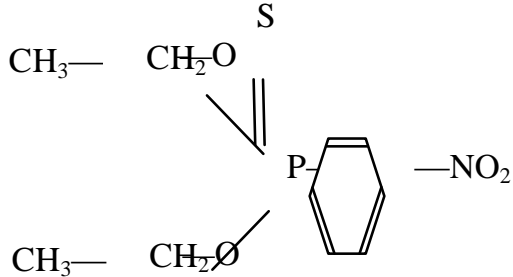<smiles>CCO[P+]1(=S)CCCCC1</smiles>$$
\mathrm{CH}_{3}
$$<smiles>COCC(=O)P(CCO)COC</smiles>

of lead brick in human body, while lead powder has the opposite effect[10].

Temperature.

The higher the temperature is, the faster volatile toxic substance evaporate, and the higher concentration of toxic steam is produced. Meanwhile, skin and pore of human expand in hot and humid seasons, which increase perspiration and blood circulation, as well as intoxication. Therefore, it is necessary to paid more attention on gas defense in fire ground due to the high temperature radiation of the fire.

\section{B. Inflammability when Wet}

Within inorganic and toxic substances, cyanides and selenides of metals are mostly non-combustible themselves, but are combustible in case of water. Cyanides of metals, such as potassium, sodium, calcium, zinc, silver, mercury, barium, copper, cadmium, cerium, lead and nickel, can release highly toxic and inflammable gas of hydrogen cyanide in case of water or damp. Selenides of $\mathrm{CdSe}, \mathrm{ZnSe}, \mathrm{FeSe}, \mathrm{PbSe}$ and Se powder can release toxic and flammable gas of hydrogen selenide in case of acid, heat, acid fog or hydrolysis.

\section{Oxidizability}

Among inorganic toxic substances, oxides of antimony, mercury and lead themselves are oxidative but incombustible. For example, five oxidation two antimony (antimony anhydride) is incombustible but has strong oxidizability, and decomposes at 380 oC . Substances of leaching tetroxide (read leaching), hydrargyri oxidum rubrum (red mercuric oxide), thallium nitrate, mercury nitrate and vanadium pentoxide are incombustible themselves, but they are weak oxidizer and decompose at $500 \mathrm{oC}$. When these toxic substances contact with combustible substances, it is very easy to cause fire and explosion, as well as highly toxic gases. 


\section{Inflammbility}

Many kinds of 1049 toxic substances on the List of dangerous goods are inflammable transparent or oil liquid. For example, flash points of ethyl bromide, trifluoroacetone and ethyl trifluoroacetoacetate are below to $-20 \mathrm{oC},-1 \mathrm{oC}$ and $-1 \mathrm{oC}$, respectively. Organic halogens of alcohols, ketones, aldehydes and esters, as well as organics of phosphorus, sulfur, chlorine, arsenic, silicon and amine, are Class $\mathrm{A}, \mathrm{B}$ or $\mathrm{C}$ liquids or combustible powder, while pesticides such as malathion are Class $\mathrm{C}$ liquids. All these toxic substances have considerable toxicity and certain inflammability. Aromatic, fused ring and heterocyclic compounds compounds of nitrobenzene and phenanthrene, as well as natural and organic toxic substances of nicotine, can burn when meet open fire and release toxic gas when meet high heat.

\section{E. Explosibility}

Some toxic substances and aromatic compounds, such as sodium azide, 2,4-dinitro chlorides, naphthol and sodium phenoxide, can cause explosion and release toxic gas when meet high heat and compact. For example, 2,4Dinitrochlorobenzene has strong toxicity and can cause explosion when meets open fire or is heated above $150 \mathrm{oC}$. Explosive materials sensitive to compact can be produced

when arsenic triiodide meets metals of potassium and sodium.

\section{SAFETY MANAGEMENT OF TOXIC SUBSTANCES}

\section{A. Warehouse's SafetyFacilities Requirements}

Warehouse should has good ventilation and heat dispersion $(15 \sim 30 \mathrm{oC})$, fire prohibition, sunscreen, water proof, moistureproof (humidity $<65 \%, 20 \mathrm{~cm}$ board under stacking), theft proof and loss prevention. In reservoir region, functional planning should be reasonable, fire channel should flow, and fire fighting facilities should complete standards.

\section{B. Security System Requirements}

Management stuff are required to hold certificates. Five dual management system that is double check, double keeping, double delivery, double book account and double lock, and measures such as being on duty and shifting duty, safety inspections must be improved and carried out.

\section{Storage Requirements}

Toxic substances should be strictly classified, specially stored and managed. It is necessary to keep complete packaging, clearly marked, and it is forbidden excessive storage, blending storage with things like food, drinks, rice, feed and daily necessities, and mixing storage with oxidant, acid, alkali, salt, inflammables and metal powder.Strengthen the Propaganda and Education of Fire Safety Management about Cultural Relic Building to Form Comprehensive Management .

\section{Perfect the Law Constructio Handling Rrequirements}

Workers should do a good personal protection (wear protective clothing, masks, gloves, follow the prohibition of hand contact with the drug, or wear gas masks, etc.). It is prohibited to shoulder, bear, diet and smoke. After working, workers should bath and dress first. When loading and unloading, the load of machine tools should be reduced appropriately in accordance with regulations. Scattered toxic substances should be gently collected and timely transferred to a safe zone to disposal without any residual. It is forbidden to extinguish fire with water and foam in case of warehouse fire of toxic substances such as hydrogen cyanide.

\section{E. Transport Requirements.}

The driver must hold certificate and drive on the transport route and time approved by the public security department. It is prohibited to transport toxic substances mixed with food, rice, beverages, daily necessities etc., neither mixed transport with explosive goods, oxidizing agents, nor with other combustible substances. It is required packaging integrity, good loading, safe driving. It is prohibited to park on the way of transportation and long time park outside station, and transportation by waterway.

\section{CONCLUSIONS}

The management work of the toxic substance should be led by the government with the active cooperation and independent work of function departme. All levels of organizations and units should carry out responsibilities assigned by the fire management, eliminate and regulate existing fire risk, and establish standard fire protection environment gradually. With the increase input of money and the strengthened fire protection management of Toxic substance, the fire protection design for Toxic substance should be complied reasonably to establish and perfect fire fighting facilities according to the urban environment. Moreover, the perfection of law construction about the Toxic substance can promote the process of legalized management. In a word, the fire protection work of the Toxic substance should be guided by scientific development view to ensure the safety management.

\section{REFERENCES}

[1] Feng Jizhen, Jiao Qiuhong. Treatment and analysis of acute chlorine poisoning[J]. The People's Liberation Army Journal of Preventive Medicine, 2002, 6, 20(3): 225

[2] Yang Lihong. Measures and Countermeasures to strengthen the management of pesticide $[\mathrm{J}]$. Pesticide science and management, 2012, 33(4): 7 9.

[3] Chen Meibao, Wang Wenhe. Basic knowledge of hazardous chemical safety[M]. Beijing. China Labour \& Social Security Publishing House, 2010.

[4] Fire Department of the Ministry of public security of the people's Republic of China. China Fire Manual: The seventh volume of hazardous chemicals, special agents and dust[M]. Shanghai: Shanghai Science and Technology Press, 2006..

[5] Tang Chaogang. Fundamental safety management of hazardous chemicals[M]. Beijing : China Machine Press, 2014.

[6] Zhao Qingxian, Shao Hui, Ge Xiukun. Safety management of hazardous chemicals[M].. Beijing. China Petrochemical Press, 2010

[7] Su Hualong. Safety management of hazardous chemicals [M] Beijing. Chemical Industry Press, 2006.

[8] Su Hualo. Safety management of hazardous chemicals [M] .Beijing, Chemical Industry Press, 2006Guo Zhiyuan. Disscussion on Firefighting Safety Countermeasures of Ancient Architecture. Shanxi Architecture[J], 2015 , 8, 41(24):250 251.

[9] Li Tao, Zong Yijing etc. Management Control Study of Toxic and Harmful Substances in Consumer Goods. Materials Review[J], 2014, 5, 28(23): 361 363

[10] Huo Jianwu, Ma Pengyou. Rethinking on the management of toxic and harmful substances in laboratories of colleges and university in the new period. University Education [J], 2013, 7(23): 151 153 